\title{
Prediction of near-surface wind fields using the CSIR Varsha GCM
}

\author{
Arshad Shameem C. and T. N. Venkatesh \\ Flosolver Unit, CSIR-National Aerospace Laboratories, Bangalore-17, \\ e-mail: $\{$ arshad,tnv\}@flosolver.nal.res.in
}

\begin{abstract}
Estimation of wind speeds and direction a few days in advance is of importance for optimum use of wind-power. Numerical weather prediction models now have sufficient skill and can be used for making short-term forecasts. A proper assessment of the model skill at specific ground stations is required before their use. Using the Varsha GCM of CSIR-NAL, a study has been carried out comparing the simulations with observed winds at a few ground stations in Karnataka. A quantification of the accuracy of the forecast is made in this paper. We find that the model captures the overall trends in wind during a day well. The correlation with observations is reasonable up to three days in advance.
\end{abstract}

\section{Introduction}

Wind is source of renewable energy which holds the promise, particularly in south India. Prediction of the prevailing winds and resulting power is an important part of the activity. Since numerical models based on the governing equations of motion are being increasingly used for this purpose, it is important to assess how these codes compare with the observations.

Numerical weather prediction has gained a foothold in India, over the last few decades. Operational forecasts are being done with high-resolution models at the India Meteorological Department (IMD). Research using numerical models is being done at various centres such as National Centre for Medium Range Weather Forecasting (NCMRWF), Noida [1], Indian Institute of Tropical Meteorology (IITM), Pune [2] Indian Institute of Science (IISc.) Bangalore [3] and CSIR labs [4].

The Varsha General Circulation Model (GCM), is a weather prediction code developed at Flosolver Unit of the CSIR - National Aerospace Laboratories (NAL), Bangalore. The Varsha model has its roots in the National Centers for Environmental Predictions (NCEP) T-80 code that was parallelized at NAL in 1993 [5]. This model solves the governing equations of the atmosphere around the globe and includes parametrization of all known physical processes in the atmosphere [6]. Spectral method is used for better accuracy in computing the horizontal derivatives of model variables. A significant feature of the Varsha GCM is the boundary layer module $[7,8]$ with "heat-flux" scaling, which is more appropriate for the low winds which are generally present over India. A sample weekly wind forecast climatology using the Varsha GCM during the monsoon months is shown in figure 1. 
The Varsha model has been mainly used for monsoon simulations on the monthly scale and real-time forecasts on an experimental basis are being sent during the monsoon months to IMD since 2007. In addition, the model has been tested for predictions on the seasonal scale as part of a model inter-comparison project [9]. The model has also been used for cyclone track and intensity predictions $[8,6]$. An attempt was also made to study the monthly means of hourly average wind forecasts over India using Varsha GCM [10]. The limitations of the model have been studied and it has been found that the RMS errors of various quantities increase with forecast length: Reasonable correlation is present up to 15 days for large-scale wind up to 10 days for all India rainfall [11].
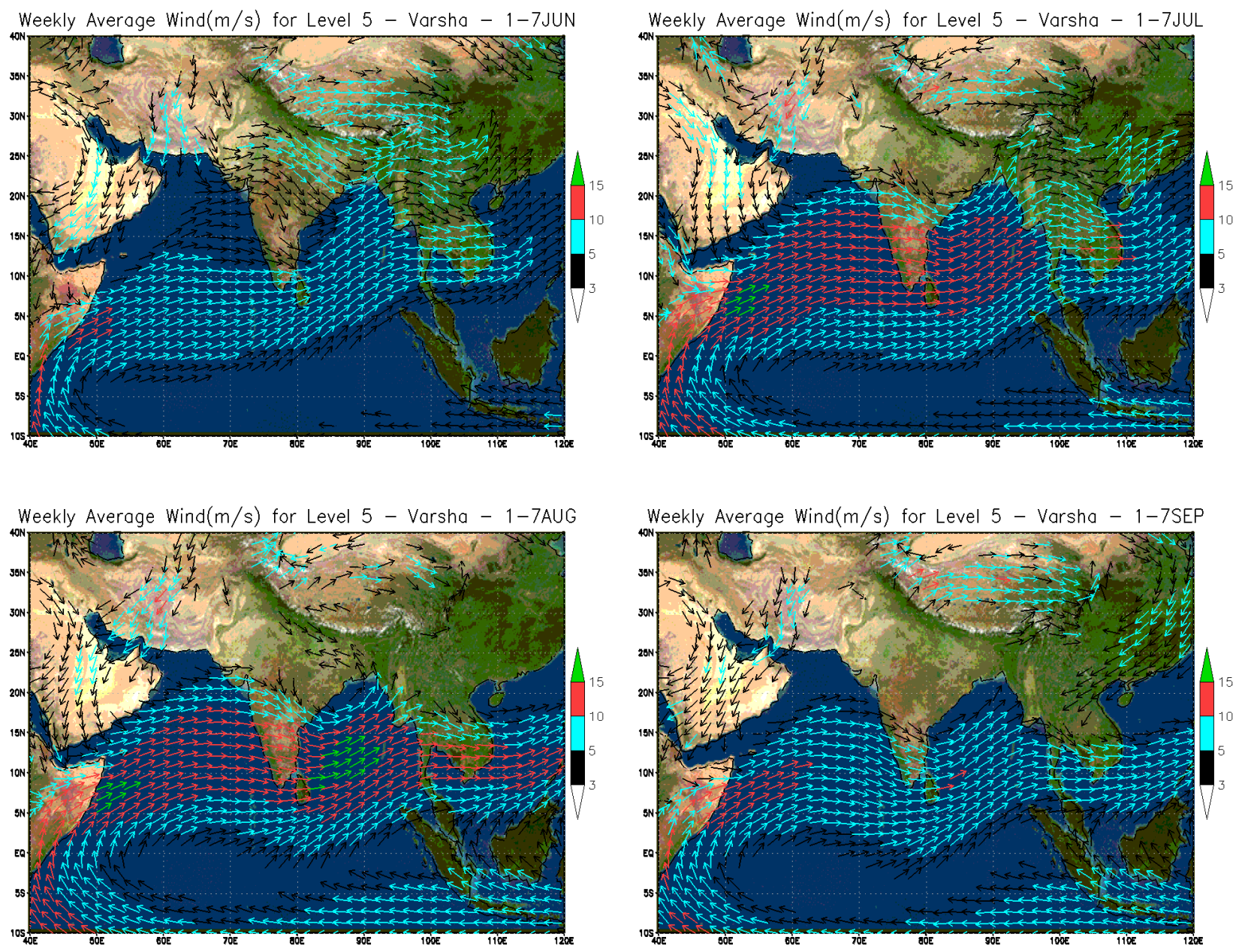

Figure 1: Weekly averaged wind climatology from Varsha GCM for the first week of monsoon months

The current study is a preliminary performance analysis of the Varsha GCM in predicting the temporal variation of wind at ten ground stations, using data provided by the Karnataka Renewable Energy Development Limited (KREDL). The details of ten of these stations are given in table 1 and the geographical distribution are marked in Figure 2. 
Table 1: Details of the KREDL wind observing stations

\begin{tabular}{|c|c|l|c|c|}
\hline Sl.No & Station Id & \multicolumn{1}{|c|}{ Station Name and Location } & Longitude & Latitude \\
\hline 1 & 5001 & Hire Gudda, Siddapur,Biligi Tq & $75.56^{\circ} \mathrm{E}$ & $16.33^{\circ} \mathrm{N}$ \\
\hline 2 & 5002 & Hunchi Benchi,Halagali,Mudhol Tq & $75.48^{\circ} \mathrm{E}$ & $16.38^{\circ} \mathrm{N}$ \\
\hline 3 & 5003 & Gudur,Hungund Tq & $75.89^{\circ} \mathrm{E}$ & $15.96^{\circ} \mathrm{N}$ \\
\hline 4 & 5004 & Guledagudda, Badami Tq & $75.79^{\circ} \mathrm{E}$ & $16.06^{\circ} \mathrm{N}$ \\
\hline 5 & 5005 & Athni, Belgaum district & $75.11^{\circ} \mathrm{E}$ & $16.77^{\circ} \mathrm{N}$ \\
\hline 6 & 5006 & Naganur, Haveri & $76.13^{\circ} \mathrm{E}$ & $16.65^{\circ} \mathrm{N}$ \\
\hline 7 & 5007 & Sankanur, Chitapur Tq & $77.11^{\circ} \mathrm{E}$ & $16.96^{\circ} \mathrm{N}$ \\
\hline 8 & 5008 & Yennihosahalli, Chalageri & $75.73^{\circ} \mathrm{E}$ & $14.55^{\circ} \mathrm{N}$ \\
\hline 9 & 5009 & Naganur, Haveri & $75.34^{\circ} \mathrm{E}$ & $14.84^{\circ} \mathrm{N}$ \\
\hline 10 & 5010 & Chirdene, Channagiri Taluk & $75.82^{\circ} \mathrm{E}$ & $14.08^{\circ} \mathrm{N}$ \\
\hline
\end{tabular}

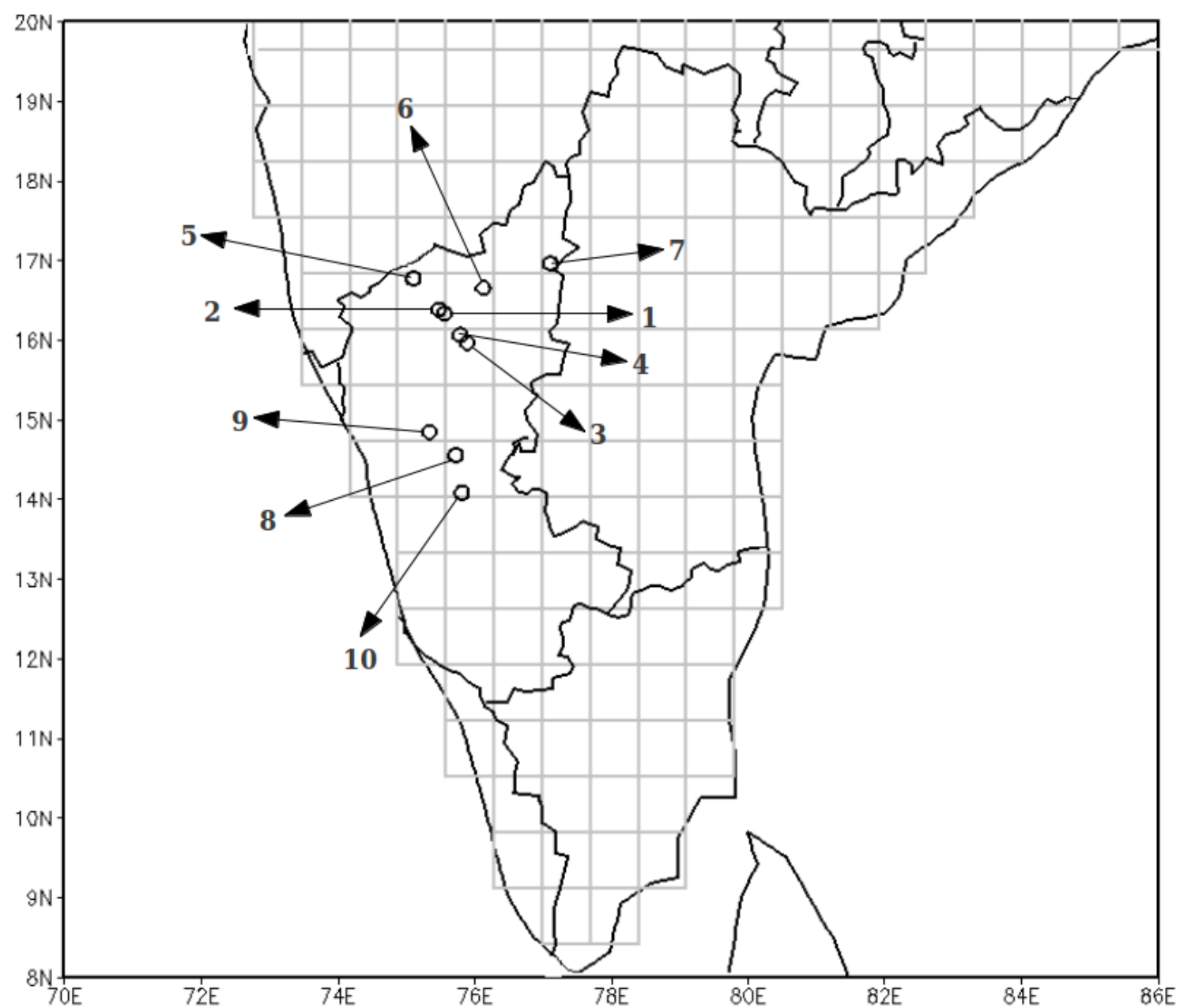

Figure 2: Geographical distribution of KREDL wind observing stations 


\section{Data and Methodology}

In this study, we used KREDL wind measurements at 50m above ground level (AGL) averaged for each hour of the day. The wind forecasts were made using the Varsha GCM which was run with a configuration of 120 waves in triangular truncation (transform grid has 512 points in east-west and 256 points in the north-south ), 18 layers in the vertical and a time step of 7.5 minutes. The 00UTC FNL analysis [12] of the NCEP, USA was used to initiate the model runs.

The method adopted for the extraction of data from the model to the station locations is described below

- The model code was modified to save the outputs at every time-step (7.5 minutes) on the first two sigma levels.

- The zonal $(u)$, meridional $(v)$ components of the wind and temperature at the model grid $(80 \times 80 \mathrm{~km})$ are bi-linearly interpolated to the station location (for each level).

- The height of the sigma levels is estimated by assuming a hydrostatic atmosphere.

- The $u \& v$ components of winds are linearly interpolated in vertical to the specified height.

- Mean wind speed and direction is calculated from the wind components.

To evaluate the performance of the model predictions, the following statistical indices are estimated from the data sets : Mean, Mean Error, Mean Absolute Error, Root mean square error (RMSE), standard deviation and correlation coefficient (CC).

\section{Results}

For the current study, the Varsha GCM has been integrated for five days during the Indian summer monsoon (May-September) of 2010 and the mean wind speed $(\mathrm{m} / \mathrm{s})$ is estimated for every hour for the given locations. This forecast wind speed data for each of the month were compared against the observations at ten ground stations from KREDL.

The comparison statistics of the mean wind speed, for two sample stations (numbered 5001 $\& 5005$ ) are given in tables $2-3$. Here the number of samples indicates the number of available hourly averaged observations in a month. Figure 3 and 4 shows the hourly distribution of the monthly average values of observed \& predicted wind speed at the the KREDL stations (5001 $\&$ 5005) for the months June, July, August and September.

Details of the results for all the stations are available in [13]. The overall statistics are given in table 4. One can see that the correlation coefficient for a one day forecast is greater than 0.5 for all the months. For a two day forecast, the coefficient is above 0.5 for July - September. The coefficient for day three forecast decreases to below 0.5 . 

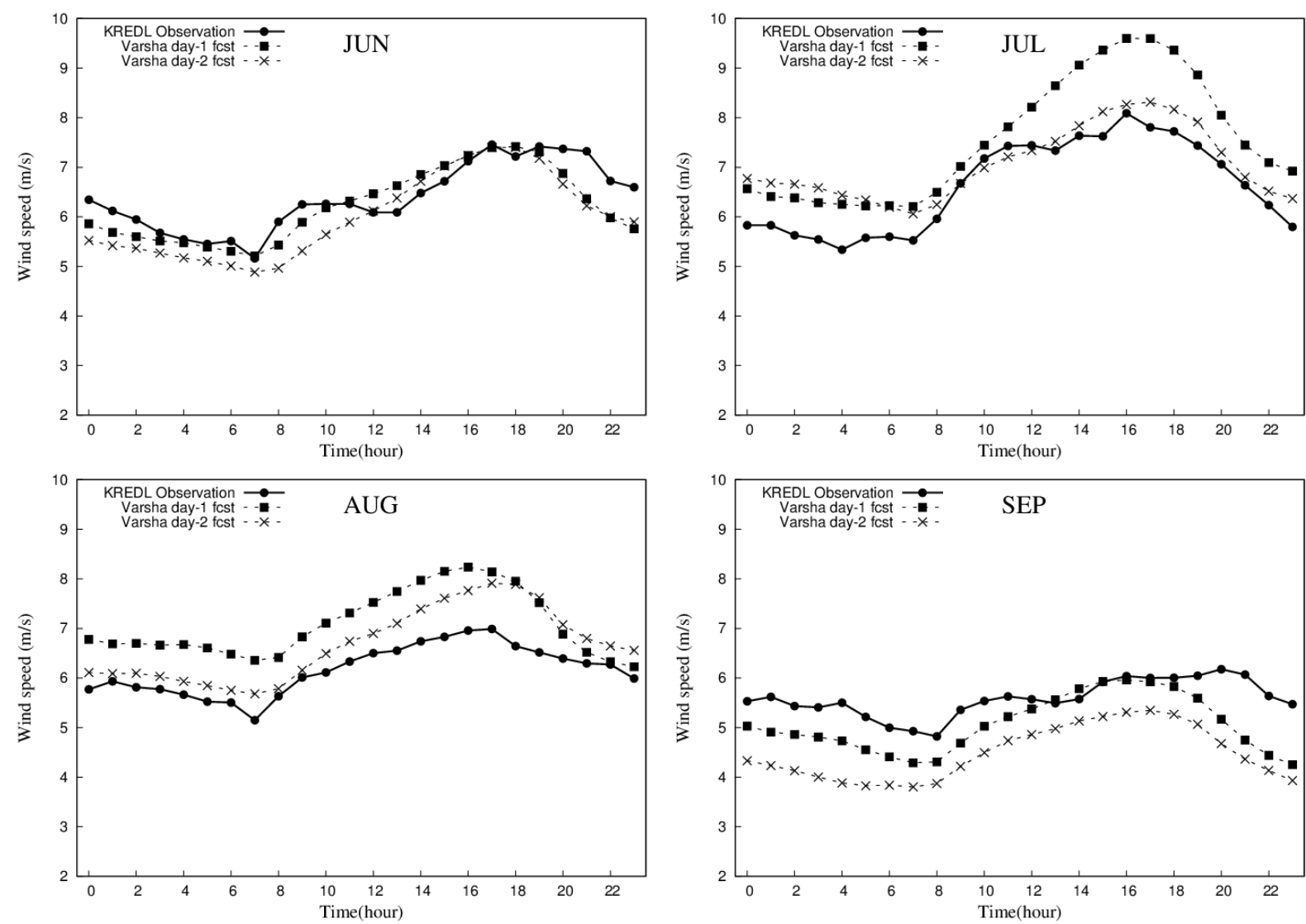

Figure 3: Hourly distribution of monthly average wind speed at the station 5001

\begin{tabular}{|l|c|c|c|c|c|c|c|c|c|}
\hline \multicolumn{10}{|c|}{$\mathbf{5 0 0 1}$} \\
\hline Month & $\begin{array}{c}\text { No of } \\
\text { Samples }\end{array}$ & $\begin{array}{c}\text { Mean } \\
\mathbf{F c s t} \\
(\mathbf{m} / \mathbf{s})\end{array}$ & $\begin{array}{c}\text { Mean } \\
\text { Obs } \\
(\mathbf{m} / \mathbf{s})\end{array}$ & $\begin{array}{c}\sigma_{\text {fcst }} \\
(\mathbf{m} / \mathbf{s})\end{array}$ & $\begin{array}{c}\sigma_{\text {obs }} \\
(\mathbf{m} / \mathbf{s})\end{array}$ & $\begin{array}{c}\text { Mean } \\
\text { Error } \\
(\mathbf{m} / \mathbf{s})\end{array}$ & $\begin{array}{c}\text { Mean } \\
\text { Abs Error } \\
(\mathbf{m} / \mathbf{s})\end{array}$ & $\begin{array}{c}\text { RMSE } \\
(\mathbf{m} / \mathbf{s})\end{array}$ & CC \\
\hline JUN & 719 & 6.22 & 6.38 & 2.25 & 2.01 & -0.16 & 1.41 & 1.84 & 0.63 \\
\hline JUL & 743 & 7.56 & 6.62 & 1.79 & 1.62 & 0.94 & 1.50 & 1.91 & 0.53 \\
\hline AUG & 743 & 7.07 & 6.16 & 1.82 & 1.84 & 0.91 & 1.50 & 1.93 & 0.57 \\
\hline SEP & 551 & 5.83 & 5.58 & 1.96 & 1.67 & 0.25 & 1.15 & 1.47 & 0.69 \\
\hline \multicolumn{8}{|c|}{$\mathbf{5 0 0 5}$} \\
\hline JUN & 719 & 7.26 & 6.58 & 2.52 & 2.40 & 0.68 & 1.96 & 2.47 & 0.54 \\
\hline JUL & 743 & 8.86 & 7.24 & 2.06 & 2.14 & 1.62 & 2.09 & 2.57 & 0.55 \\
\hline AUG & 743 & 8.15 & 6.45 & 2.12 & 2.49 & 1.70 & 2.14 & 2.68 & 0.61 \\
\hline SEP & 611 & 6.20 & 5.67 & 2.18 & 2.16 & 0.53 & 1.36 & 1.71 & 0.72 \\
\hline
\end{tabular}

Table 2: Comparison statistics for day 1 forecasts for the stations $5001 \mathscr{6} 5005$ 

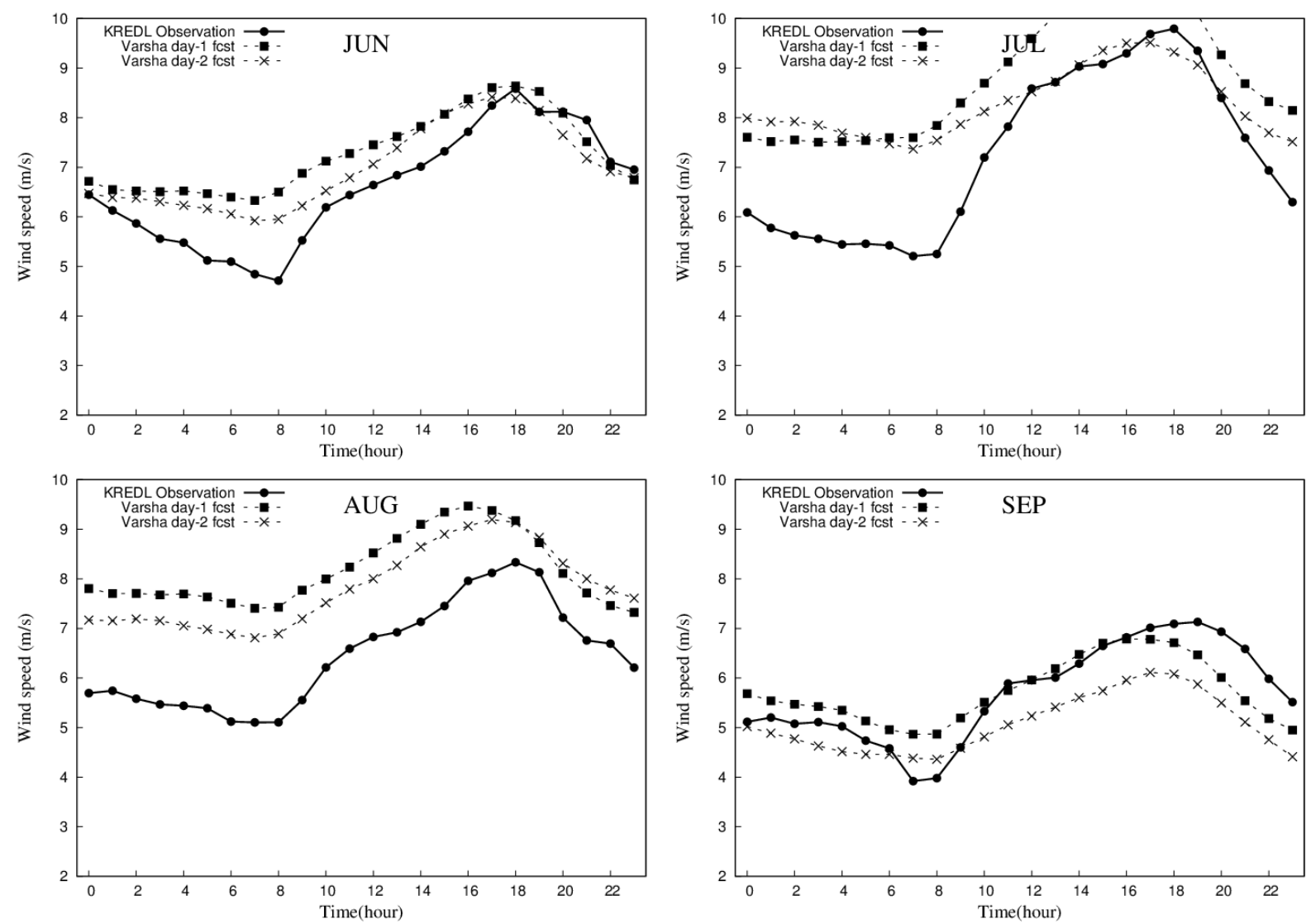

Figure 4: Hourly distribution of monthly average wind speed at the station 5005

\begin{tabular}{|l|c|c|c|c|c|c|c|c|c|}
\hline \multicolumn{10}{|c|}{$\mathbf{5 0 0 1}$} \\
\hline Month & $\begin{array}{c}\text { No of } \\
\text { Samples }\end{array}$ & $\begin{array}{c}\text { Mean } \\
\mathbf{F c s t} \\
(\mathbf{m} / \mathbf{s})\end{array}$ & $\begin{array}{c}\text { Mean } \\
\text { Obs } \\
(\mathbf{m} / \mathbf{s})\end{array}$ & $\begin{array}{c}\sigma_{\text {fcst }} \\
(\mathbf{m} / \mathbf{s})\end{array}$ & $\begin{array}{c}\sigma_{\text {obs }} \\
(\mathbf{m} / \mathbf{s})\end{array}$ & $\begin{array}{c}\text { Mean } \\
\text { Error } \\
(\mathbf{m} / \mathbf{s})\end{array}$ & $\begin{array}{c}\text { Mean } \\
\text { Abs Error } \\
(\mathbf{m} / \mathbf{s})\end{array}$ & $\begin{array}{c}\text { RMSE } \\
\mathbf{( m / s})\end{array}$ & CC \\
\hline JUN & 719 & 6.27 & 6.38 & 2.15 & 2.01 & -0.10 & 1.91 & 2.58 & 0.23 \\
\hline JUL & 743 & 6.72 & 6.62 & 1.74 & 1.62 & 0.10 & 1.35 & 1.71 & 0.48 \\
\hline AUG & 743 & 6.47 & 6.16 & 2.15 & 1.84 & 0.31 & 1.59 & 2.04 & 0.50 \\
\hline SEP & 551 & 4.79 & 5.58 & 2.34 & 1.67 & -0.80 & 1.79 & 2.21 & 0.52 \\
\hline \multicolumn{8}{|c|}{$\mathbf{5 0 0 5}$} \\
\hline JUN & 719 & 7.35 & 6.58 & 2.57 & 2.40 & 0.77 & 2.43 & 3.22 & 0.21 \\
\hline JUL & 743 & 7.86 & 7.24 & 2.01 & 2.14 & 0.62 & 1.81 & 2.24 & 0.46 \\
\hline AUG & 743 & 7.62 & 6.45 & 2.41 & 2.49 & 1.17 & 2.27 & 2.78 & 0.47 \\
\hline SEP & 611 & 5.34 & 5.67 & 2.82 & 2.16 & -0.34 & 1.87 & 2.42 & 0.56 \\
\hline
\end{tabular}

Table 3: Comparison statistics for day 3 forecasts for the stations 5001855005 


\begin{tabular}{|l|c|c|c|c|c|c|c|c|}
\hline \multicolumn{7}{|c|}{ Day1 } \\
\hline Month & $\begin{array}{c}\text { Mean } \\
\text { Fcst } \\
(\mathbf{m} / \mathbf{s})\end{array}$ & $\begin{array}{c}\text { Mean } \\
\text { Obs } \\
(\mathbf{m} / \mathbf{s})\end{array}$ & $\begin{array}{c}\sigma_{\text {fcst }} \\
(\mathbf{m} / \mathbf{s})\end{array}$ & $\begin{array}{c}\sigma_{\text {obs }} \\
(\mathbf{m} / \mathbf{s})\end{array}$ & $\begin{array}{c}\text { Mean } \\
\text { Error } \\
(\mathbf{m} / \mathbf{s})\end{array}$ & $\begin{array}{c}\text { Mean } \\
\text { Abs Error } \\
(\mathbf{m} / \mathbf{s})\end{array}$ & $\begin{array}{c}\text { RMSE } \\
(\mathbf{m} / \mathbf{s})\end{array}$ & CC \\
\hline JUN & 6.05 & 5.82 & 2.11 & 1.92 & 0.22 & 2.19 & 2.64 & 0.50 \\
\hline JUL & 7.15 & 6.09 & 1.78 & 1.70 & 1.05 & 2.11 & 2.50 & 0.50 \\
\hline AUG & 6.80 & 5.56 & 1.83 & 1.90 & 1.23 & 2.17 & 2.56 & 0.56 \\
\hline SEP & 5.45 & 4.93 & 1.96 & 1.63 & 0.52 & 1.59 & 1.92 & 0.67 \\
\hline & & & & & \\
\\
\hline
\end{tabular}

Table 4: Overall comparison statistics for day 1, day $2 \&$ day 3 forecasts

\section{Conclusion}

From this study we find that the Varsha GCM is able to simulate the wind at most of the locations with reasonable accuracy. The correlation coefficients for day-1 predictions against observations are equal or above 0.5 for all the four months. As expected the value of correlation coefficient decreases with forecast length. One should note that the Varsha GCM is a global model of horizontal resolution of $80 \mathrm{~km}$ and for this study the wind values have been interpolated to the station locations. In the vertical Varsha GCM computes the wind at discrete model levels - the lowest two levels being at about $45 \mathrm{~m}$ and $170 \mathrm{~m}$. Analysis of results presented in tables and figures show that

- The diurnal trend in wind speed is picked up well by the Varsha model forecast.

- The daily mean forecast wind exceeds $6 \mathrm{~m} / \mathrm{s}$ in July and August.

- The mean absolute error between the prediction and observation is higher in June and lower in September.

- For most of the stations model predicted wind speeds are systematically lower than the observed values. This is due to the fact that model predicts average wind speed within a grid area $(80 \mathrm{~km} \mathrm{X} 80 \mathrm{~km})$ while wind farms are located at sites with maximum wind 
speed. A systematic correction applied using large sample of observed data will improve the forecast.

- Value of the correlation coefficient decreases with forecast length as expected.

- Monthly averages of hourly mean wind shows that the Varsha model forecasts are able to reproduce the time window rich for wind energy harvesting. The peak forecast wind is usually in phase with the observed peak during the monsoon months (June - September).

\section{Acknowledgments}

The authors thank KREDL for providing the data sets. Thanks are due to Dr. G. N. Dayananda and colleagues of the Wind Energy group of CSMST division for initiating this work and continued interaction. The authors are thankful to Mrs. Rajalakshmy, Head Flosolver and colleagues at the Flosolver lab for their support. We also acknowledge Dr. B. K. Basu, former head of research, NCMRWF, Delhi, for useful discussion and comments. The computations were performed on the Flosolver Mk8 parallel computing system. Thanks are also due to NCEP for providing the FNL datasets.

\section{References}

[1] Ashis K. Mitra, E. N. Rajagopal, G. R. Iyengar, D. K. Mahapatra, I. M. Momin, A. Gera, K. Sharma, J. P. George, R. Ashrit, M. Dasgupta, S. Mohandas, V. S. Prasad, Swati Basu, A. Arribas, S. F. Milton, G. M. Martin, D. Barker and M. Martin (2013), "Prediction of monsoon using a seamless coupled modelling system", Current Science, 104, 10, 1369 1379

[2] A. K. Sahai, S. Sharmila, S. Abhilash, R. Chattopadhyay, N. Borah, R. P. Krishna, S. Joseph, M. Roxy, S. De, S. Pattnaik and P. A. Pillai (2013) "Simulation and extended range prediction of monsoon intraseasonal oscillations in NCEP CFS/GFS version 2 framework", Current Science, 104, 10, 1394 - 1408

[3] Ravi S. Nanjundiah, P. A. Francis, Mohit Ved and Sulochana Gadgil (2013) "Predicting the extremes of Indian summer monsoon rainfall with coupled oceanatmosphere models", Current Science, 104, 10, 1380 - 1393

[4] K. Rajendran, S. Sajani, C. B. Jayasankar, and A. Kitoh (2013), "How dependent is climate change projection of Indian summer monsoon rainfall and extreme events on model resolution?" Current Science, 104, 10, 1409 - 1418

[5] U. N. Sinha, T. N. Venkatesh, V. Y. Mudkavi, A. S. Vasudeva Murthy, R. S. Nanjundiah, V. R. Sarasamma, Rajalakshmy S., K. Bhagyalakshmi, A. K. Verma, C. K. Sreelekha, and K. L. Resmi (2005), "Comprehensive report on the meteorological aspects of the NMITLI project on Mesoscale modelling for monsoon related predictions", NAL PD FS 0514.

[6] B. K. Basu and K. Bhagyalakshmi, (2010), "Forecast of the track and intensity of the tropical cyclone AILA over the Bay of Bengal by the global spectral atmospheric model VARSHA", Current Science, 99, 765-774. 
[7] Rao K. G. and Narasimha R., (2005), "Heat-flux scaling for weakly forced turbulent convection in the atmosphere", J. Fluid Mech., 547, 115135.

[8] T. N. Venkatesh, Vidyadhar Mudkavi, S. Rajalakshmy, V. R. Sarasamma, U. N. Sinha and R. Narasimha, (2006), "Preliminary results on the simulation of the 1999 Orissa supercyclone using a GCM with a new boundary layer code", Mausam, 57, 119-128.

[9] Sulochana Gadgil1 and J. Srinivasan (2011), "Seasonal prediction of the Indian monsoon" Current Science, 100, NO. 3, 343 - 353

[10] Manabendra M. De., Anupama K., M. Mahfooz Sheikh, S. Rajalakshmy, Arshad Shameem C., and B. K. Basu (2013), "Monthly means of hourly average wind forecasts from the Varsha global atmospheric model at 60 metres above ground" NAL PD-CSM/2013/1000

[11] Dhanya M., Anjali B. and T. N. Venkatesh (2008) "Assessment of monsoon rainfall and wind simulations on Flosolver using the Varsha 1.2 GCM" Proceedings of International Conference on Aerospace Science and Technology (INCAST), 26-28 June 2008, Bangalore

[12] http://rda.ucar.edu/datasets/ds083.2/

[13] Arshad Shameem C, T. N. Venkatesh, M. Mahfooz Sheikh, Anupama K., B. K. Basu (2012), "Evaluation of Varsha GCMs Near-surface wind predictions for the year 2010 for the KREDL stations ", NAL PDFS 1209 - July 2012 